\title{
Titration of Antibodies and Application of the KAP Strategy for Hepatitis B in Students and Teachers
}

\author{
Nagaraja Sreeharsha ${ }^{1,2}$, Itzjak Kadar Epstein ${ }^{3}$, Syed Mohammed Basheeruddin Asdaq ${ }^{4, *}$, \\ Abdulhakeem S. Alamri ${ }^{5,6}$, Walaa F. Alsanie ${ }^{5,6}$, Majid Alhomrani ${ }^{5,6}$ \\ ${ }^{1}$ Department of Pharmaceutical Sciences, College of Clinical Pharmacy, King Faisal University, Al-Ahsa, SAUDI ARABIA. \\ ${ }^{2}$ Department of Pharmaceutics, Vidya Siri College of Pharmacy, Off Sarjapura Road, Bangalore, Karnataka, INDIA. \\ ${ }^{3} \mathrm{P} 4$ Consultant WHO and Epidemiologist at Regional Office Ministry of Health, COLOMBIA. \\ ${ }^{4}$ Department of Pharmacy Practice, College of Pharmacy, AIMaarefa University, Dariyah, Riyadh, SAUDI ARABIA. \\ ${ }^{5}$ Department of Clinical Laboratory Sciences, The Faculty of Applied Medical Sciences, Taif University, Taif, SAUDI ARABIA. \\ ${ }^{6}$ Centre of Biomedical Sciences Research (CBSR), Deanship of Scientific Research, Taif University, Taif, SAUDI ARABIA.
}

\begin{abstract}
Aim: Hepatitis B can be prevented through a complete vaccination scheme. In clinical practice, dentistry personnel is 6 times more likely to get this disease than people who perform other activities. To determine the level of protection and establish the degree of knowledge, attitudes, and practices (KAP) against Hepatitis B in the students and clinical lecturers in a dental clinic. Methods: Descriptive cross-sectional study. For the KAP strategy, a structured survey was applied with 15 questions, and for the titration: antibody level, concentration according to five categories ranging from negative or very poor to highly positive. The analysis of blood samples is carried out using ELISA in an immunology and molecular biology laboratory. Results: $71 \%$ of people present concentrations equal to or greater than $20 \mathrm{mlU} / \mathrm{ml}$. In the KAP strategy, the highest rating was in the practical compo-nent with $50.8 \%$, followed by knowledge with $40 \%$, an acceptable score, and attitudes $27.7 \%$ with an insufficient score. Within this survey, $38 \%$ of the participants know the routes of transmission for Hepatitis B, $51 \%$ present the complete vaccination scheme, and $75.4 \%$ report not having been involved in an accident with biological risk. Conclusion: KAP strategy, knowledge about Hepatitis B; was represented in the acceptable rating, insufficient attitudes, and outstanding practices
\end{abstract}

Key words: Hepatitis B, Antigen, Antibody, ELISA, Hemodialysis.

\section{INTRODUCTION}

Hepatitis B is currently a public health problem, as it is one of the most frequent infectious diseases in the world with greater geographic distribution. The highest prevalence is recorded in Sub-Saharan Africa (countries on the African continent that do not border the Mediterranean Sea) and East Asia according to WHO reports. In Colombia, the prevalence of carriers of the surface antigen against Hepatitis $B$ (HBsAg) 40 years ago was 3\%, being an intermediate endemic country with hyperendemic in some areas located in the north and the Amazon in the south; for this reason, universal vaccination was introduced for newborns and children under 5 years old in 1993. Currently, the largest number of Hepatitis B cases come from Bogotá (16.57\%), Antioquia (15.84\%), Norte de Santander (8.08\%), Valle (6.90\%), and Santander $(4.36 \%) .{ }^{1}$ The groups that present the highest risk for infection are those with occupational ex-posure (health personnel, health students, sanitary cleaners) cohabitants who are acutely ill or carry the virus, newborns of mothers carrying the virus, patients in hemodialysis programs, patients in transplant programs, patients requiring multiple transfusions of blood or blood products (hemophilia, thalassemia), sexual promiscuity, travelers to endemic areas (Africa, Asia, Amazon), drug addicts,
Submission Date: 05-06-2021; Revision Date: 17-07-2021; Accepted Date: 24-08-2021

DOI: 10.5530/ijper.55.3s.171 Correspondence: Dr. Sree Harsha Nagaraja, Associate Professor, Department of Pharmaceutical Sciences, College of Clinical Pharmacy, King Faisal University, Al-Ahsa-31982, SAUDI ARABIA.

Phone: +96-653-548-5322, Email -sharsha@kfu.edu.sa

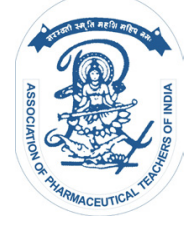

www.ijper.org 
individuals subjected to punctures (tattoos, acupuncture). Hepatitis B is an infectious-contagious disease, which occurs as a consequence of a weak immune state which leads to the destruction of some hepatocytes that express viral antigens, therefore the persistence of the virus will trigger a chronic necro-inflammatory liver disease of a nature that activates the fibrogenesis process and can lead to hepatocarcinoma, $90 \%$ of infections in adults heal spontaneously without leaving sequelae. The disease is classified as acute and chronic, the acute is characterized by the presence of HBsAg and immunoglobulin $\mathrm{M}(\mathrm{IgM})$ in the nucleus, in this initial phase the patients are seropositive for the surface antigen for Hepatitis B (HBsAg), this antigen is strongly replicated and its presence in blood and fluids. ${ }^{2}$

The body has a high risk of contagion. From the moment of exposure to the virus until the disease manifests, one to six months elapse, the signs and symptoms can last sever-al days and even weeks these are jaundice, extreme fatigue, vomiting, nausea, and abdominal pain. Chronic hepatitis B is characterized by the persistence of HBsAg for more than six months, which is the main marker of the risk of suffering liver diseases such as insufficiency and cirrhosis later. The chronic picture is characterized by being asymptomatic, among the signs and symptoms are cirrhosis, hepatocarcinoma, and death. ${ }^{3}$

The transmission mechanisms of the Hepatitis B virus are the parenteral, sexual, vertical, and horizontal routes. The parenteral route is the oldest known form and the highest risk in health professionals occurs through needles, contaminated blood products. Vaccination is safe and highly effective, it confers protection to more than $90 \%$ of vaccinated individuals, dentists have six times the risk of acquiring the virus due to high exposure to oropharyngeal secretions such as blood and saliva, it is a requirement to have the complete vaccination scheme. $^{3}$

HBsAg functions as an important serological marker that becomes detectable in serum after an incubation period of 4 to 10 weeks. Infected individuals can transmit the infection one to two months before the first symptoms and are infective throughout the acute course of the disease and in the chronic carrier phase, which persists for years. It is called chronic hepatitis when the presence of HBsAg in serum is reported for more than six months and due to alterations in liver function (elevated transaminases, bilirubin and alkaline phosphatase). ${ }^{4}$

The verification of the level of antibodies must be carried out three months after completing the complete vaccination scheme through the quantification of antibodies against the Hepatitis B virus ( $\mathrm{HBsAb}$ ), considering $20 \mathrm{mIU} / \mathrm{ml}$ or more protective. The evaluation of seroconversion is crucial because each individual has a capacity that varies according to various factors depending on the host (alcohol, cigarette, muscle mass, age, gender, presence or absence of maternal antibodies) and the vaccine (nature and a dose of the antigen, mode of administration, use or not of an adjuvant, use or not of a carrier protein). Also, some people do not create the appropriate level of antibodies despite applying the 3 doses which are called nonresponders. ${ }^{5}$

This research is important because it will help to update both; the teachers (clinical lecturers), the students, and the health personnel of the clinic of the faculty of dentistry of the institution, regarding the knowledge about the vaccine, its risks, the pertinent recommendations, and the immune protection status. Having the antibody titration test against Hepatitis B is useful as student support in the clinical area, as a contribution to the resume in the part biosecurity barriers, blood tests, protection; practices: Hepatitis B protocols, number of doses, follow-up of the vaccination scheme, an accident with biological risk, blood tests.

\section{Antibody titration: antibody level, concentration.}

For the KAP strategy, a structured survey is applied with 15 questions, five for each of the criteria. Which is scored according to the number of correct questions with criteria ranging from excellent to poor. (Table 1). It was required to determine the level of antibody titration through the ELISA test and to establish the degree of knowledge, attitudes and practices through the KAP strategy against the Hepatitis B virus, presented by the students and teachers of the dental clinic.

\section{MATERIALS AND METHODS}

The type of study is descriptive, cross-sectional. The population was made up of 65 people where 53 were students and 12 teachers belonging to the clinic of the dental school (Table 1).

\begin{tabular}{|c|c|c|}
\hline \multicolumn{3}{|c|}{ Table 1: Study population. } \\
\hline Sample Size & Number & $\%$ \\
\hline Students & 53 & $81.5 \%$ \\
\hline Clinicians & 12 & $18.5 \%$ \\
\hline & 65 & 100 \\
\hline
\end{tabular}




\begin{tabular}{|c|c|c|}
\hline \multicolumn{3}{|c|}{ Table 2: Immunization level. } \\
\hline Negative & $0-10 \mathrm{mlU} / \mathrm{ml}$ & \multirow{2}{*}{ Non protected } \\
\hline Grey zone & $11-20 \mathrm{mlU} / \mathrm{ml}$ & \\
\hline Positive-Low & $21-50 \mathrm{mlU} / \mathrm{ml}$ & \multirow{2}{*}{ Protected } \\
\cline { 1 - 2 } Positive-moderate & $\begin{array}{c}51-200 \mathrm{mlU} / \mathrm{ml} \\
\text { Positive-high }\end{array}$ & $\begin{array}{c}200 \mathrm{or} \mathrm{more} \mathrm{mlU} / \\
\mathrm{ml}\end{array}$ \\
\hline
\end{tabular}

For the titration of antibodies, the analysis of blood samples is carried out by means of ELISA in the immunology and molecular biology laboratory (Table 2).

The variables analyzed in this study correspond to:

"Socio-demographic: Gender (male, female); age range (20-25, 26-30, 31-35. 36-40, over 41), type of population (students and clinicians).

"KAP strategy: knowledge: immune-preventable disease, number of doses, transmission routes, duration of immunization, an accident with biological risk; attitudes: The procedure was carried out taking into account the following phases:

First phase: Informed consent each participant signed authorizing to be part of the re-search, understanding the objectives and accepting the minimum risks.

Second stage: Completion of the KAP survey. It was applied directly and personally, evaluating transmission routes, number of doses, biological risk, barriers to biosecurity, previous analysis, and vaccination schedule. Third phase: Blood sampling: it was carried out in two days with the help of a nursing assistant and under the supervision of the adviser, a bacteriologist specializing in hematology. On the first day, 48 samples were taken on the second day 17 samples. Each tube was labeled with an identification number, name, and sequential code. Fourth phase: Processing: The samples were taken to the immunology and molecular biology laboratory for the centrifugation process (3000 rpm for $10 \mathrm{~min}$ ). Utilizing a pipette the serum was extracted and deposited in vials with its respective label. Once the process was finished, they were refrigerated at $-20^{\circ} \mathrm{C}$.

Fifth phase: ELISA test: antibodies against the surface antigen of the hepatitis B virus were quantitatively determined in serum by means of the ELISA test (direct immuno-enzymatic assay), the Dia.Pro ${ }^{\circledR}$ brand kit was used following the manufacturer's instructions and complying with the standardized steps of the technique.

\section{RESULTS}

The $77 \%$ of those evaluated, corresponding to 40 students and 10 teachers, are protected. (Figure 1).

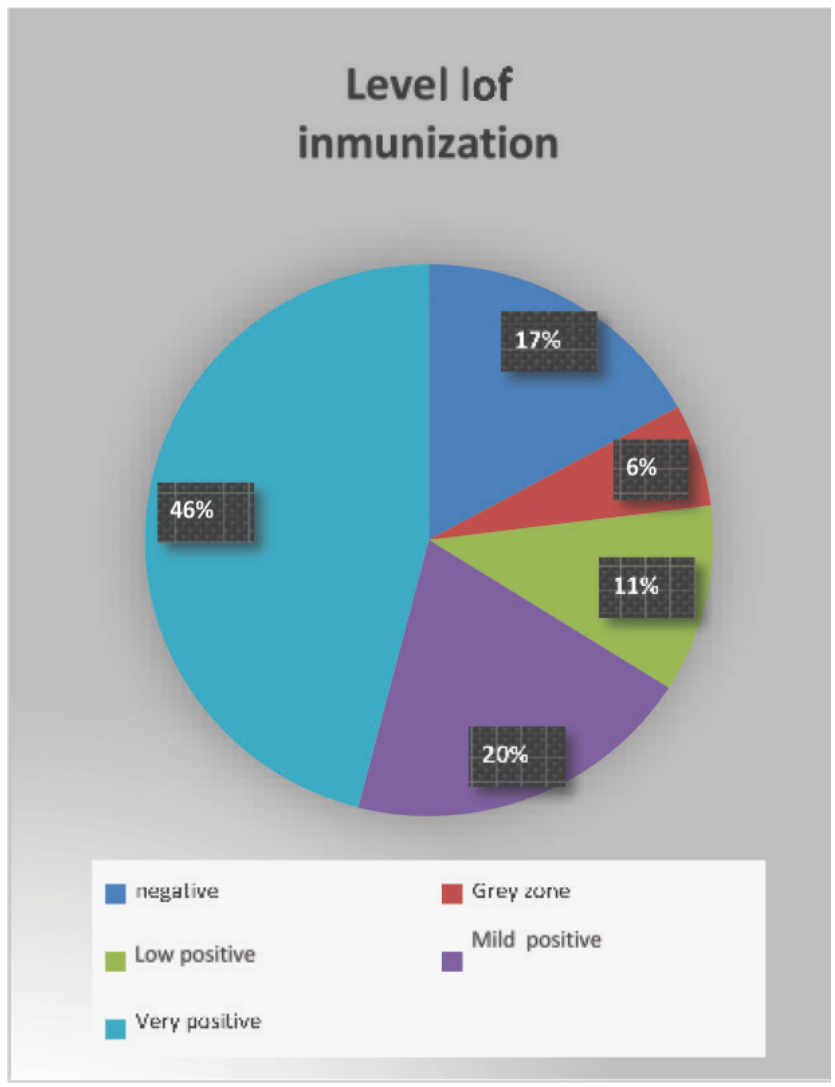

Figure 1: Study Population.

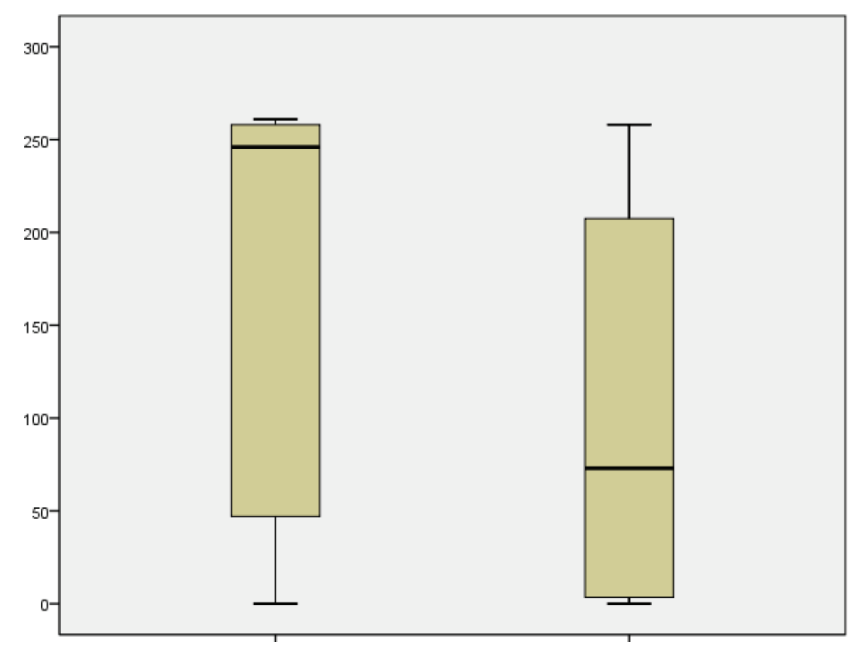

Figure 2: Correlation between antibody concentration and gender. Antibody concentration Y-axis, Sex; Male and Female respectively.

There was no significant difference in the concentration of antibodies regarding gender (Figure 2).

When correlating the number of doses and the antibody concentration, the highest mean is one dose with a concentration of $173 \mathrm{mIU} / \mathrm{ml}$, followed by four doses with $155 \mathrm{mIU} / \mathrm{ml}$. 
The highest grade was outstanding in practices with $50.8 \%$; In knowledge, a higher score was obtained in acceptable with $40 \%$ and insufficient with $27.7 \%$ in attitudes.

When correlating the KAP strategy and the antibody concentration, the highest mean is deficient with a concentration of $215 \mathrm{mIU} / \mathrm{ml}$, followed by excellent with $182 \mathrm{mIU} / \mathrm{ml}$.

\section{DISCUSSION}

There are certain parameters to achieve the ideal degree or level of immunization. A person who has not received any doses or, on the contrary, they have been given but did not reach a sufficient level of antibodies that exceed $10 \mathrm{mIU} / \mathrm{ml}$ is a person at risk of contagion. Those that are in the range of $11-20 \mathrm{mIU} / \mathrm{mL}$, also known as the gray area as they call it in the laboratory, have antibodies, but not enough to protect it from contagion. $21-50 \mathrm{mIU} / \mathrm{mL}$ is considered a low positive level, indicating that they are protected, but a reinforcement would further increase the degree of protection as achieved in the range $51-200 \mathrm{mIU} / \mathrm{ml}$ or highly positive. Above $200 \mathrm{mIU} / \mathrm{ml}$ is considered the ideal level to achieve protection. ${ }^{6}$

When correlating the number of doses and the concentration of antibodies, the highest antibody levels were found with a mean of $173 \mathrm{mIU} / \mathrm{ml}$ in those who received only one dose, unlike the other results that were ascending directly proportional to the number of doses, in those who received two doses the mean is $131 \mathrm{mIU} / \mathrm{ml}$, those who received three doses the mean is $147 \mathrm{mIU} / \mathrm{ml}$ and those with four doses the mean 155 $\mathrm{mIU} / \mathrm{ml}^{7}$

The ability of an individual to create antibodies is multifactorial, dependent on the host, and the vaccine. Host-dependent factors are age, gender, habits such as smoking and alcohol, being overweight, and the state of the immune system. In young people, the immune system has a greater response than in people over 40 years of age. Regarding gender, women have shown greater seroprotection than men. Habits such as smoking and alcohol influence reducing the ability to produce antibodies. Altered immune response due to impaired function of lymphocytes or macrophages or peripheral vasoconstriction induced by the action of nicotine maybe some of the possible explanations. In individuals with a body mass index $>30$, the response to the vaccine is lower than in those without overweight (BMI 20-25), an increase of 5 units in the body mass index represents a parallel increase of 1.6 times in the risk of a nonimmunizing response. Immunocompromised patients, chronic kidney failure, immunosuppressive treatment (eg hemodialysis), inflammatory bowel disease have a lower percentage of seroconversion in some cases from 50 to $70 \% .^{7}$

Another factor that could influence seroconversion is that starting in 1993 in Colombia vaccination was implemented for all newborn children against Hepatitis B, $47.7 \%$ of the sample studied were born during this date, which is why it follows that received the vaccine. People who created antibodies at an early age, when vaccinated again stimulate immune memory, thus obtaining a higher level of antibodies.

The aforementioned response to the results obtained, where cases were recorded in which, despite not presenting the complete vaccination scheme, they achieved adequate levels of protection, compared to other cases where the complete vaccination scheme was, however, they did not reach protection levels.

The study found that $68.68 \%$ of men had an adequate level of protective antibodies (> $20 \mathrm{mIU} / \mathrm{ml}$ ), being higher in women with $87.76 \%$. In agreement with the literature which reports that being male implies a risk factor for the decrease of the immunogen-ic capacity of the vaccine. The literature reports that in the first vaccination dose up to $70 \%$ coverage is reached, in the second $90 \%$ and the third $99 \%$ and carried out an observational and analytical study in subjects vaccinated against the hepatitis B virus from Health Area nine of the Valencian Community $(n=827)$. After vaccination, determined the titration of surface antibodies to check the response, considering protective levels higher than $10 \mathrm{mIU} / \mathrm{ml}$. When analyzing the response according to sex, seroconversion was observed in $95.9 \%$ of women and $87.8 \%$ of men. ${ }^{8,9}$

Another study carried out in Arequipa shows that 98\% of female workers had levels of antibodies considered seroprotective (>10 mIU/ml) and $2 \%$ did not reach levels of seroprotection. In male workers, 89.4\% presented levels of seroprotection. (5). The aforementioned studies consider seroprotection values $>10 \mathrm{mIU} / \mathrm{ml}$, unlike our study that establishes values $>10 \mathrm{mIU} / \mathrm{ml}$ as antibody production and not as protection against the virus, therefore, we accept as seroprotection values $>20$ $\mathrm{mIU} / \mathrm{ml}^{10}$

When analyzing the age range concerning the degree of immunization, it was found that of 31-35 years, 33.3\% of the participants are protected, and in ages, over 36 years it drops considerably to $14.3 \%$. Consistent with the literature that reports, when primary vaccination occurs after age 40 , protection decrease to $90 \%$, and after age 60 to $65 \%$ to $75 \%$. The response of the 
vaccine in neonates is of the order of $95-100 \%$, while in individuals older than 60 years it is reduced to $57.9 \%$. People over 40 years have a lower proportion of seroconversion.

Regarding the transmission routes in this study, 38\% answered adequately. When comparing the type of population, a higher percentage was found in students with $39.6 \%$ compared to teachers who obtained 33.3\%. Regarding gender, there was no significant difference, $38.8 \%$ female and $37.5 \%$ male. In the study carried out at a medical school in Medellín, the main sources of transmission were blood (90\%) and semen (65\%). In a research in which the objective was to evaluate the knowledge of Hepatitis B and its vaccination in 256 nursing students, from the data it should be noted that the students know that Hepatitis B is parenterally and sexually transmitted. ${ }^{11}$

According to the literary review, promiscuity is one of the main risk factors for acquiring this infection, followed by tattoos and, after that, the administration of intra-venous drugs. In this study, 69.2\% recognize the adequate vaccination scheme. In the study of the medical school in Medellín, only 77\% know the number of doses that are part of the complete vaccination scheme. ${ }^{12}$

In the present study, $64.6 \%$ know how to define a biological risk accident, and $24.6 \%$ report having suffered a biological risk accident. In the study carried out on nursing students, only $52.7 \%$ of those surveyed knew all the guidelines to follow in the event of a puncture and, according to the results of the survey, only $4.7 \%$ adopted sufficient measures to prevent contagion. Regarding the risk of contagion, half of those surveyed consider that it is high in health professionals and only $49.6 \%$ of those surveyed con-sider that the risk of contagion in their practices is high, however, $44.6 \%$ of those surveyed had already had accidental exposures during their internship. Only a minority answered that the risk of contagion after vaccination was eliminated.

In this study, the frequency of vaccination against hepatitis B was revealed. $81 \%$ of the participants reported having the complete vaccination schedule, $51 \%$ presented the complete schedule and $6 \%$ did not remember. The results show the importance of professional training, knowledge, and risk of infection in determining vaccination against Hepatitis $B$. In the study carried out on nursing students, the total number of correctly vaccinated students was $86.7 \%$. A study was carried out in which the purpose was to determine the prevalence of infection by the Hepatitis B virus and the vaccination status in university students from Bucaramanga, it is a descriptive cross-sectional study carried out in 2010. 1,298 students from five universities. Sero-logical markers of infection for the virus were identified by ELISA and the viral genome was detected by nested PCR. Low vaccination coverage was found in $30.2 \%$ vaccinated and $67.9 \%$ susceptible. ${ }^{13}$

Regarding the number of doses, $12 \%$ of the participants reported having a dose of the scheme, 31\% 2 doses, 40\% 3 doses, 11\% 4 doses and 6\% did not remember the number of doses received. Regarding the level of immunization, $46 \%$ of participants have ideal protection (200 or more $\mathrm{mIU} / \mathrm{ml}$ ), 20\% have high positive protection $(51-200 \mathrm{mIU} / \mathrm{ml}), 17 \%$ have negative protection $(0-10 \mathrm{mIU} / \mathrm{ml}), 11 \%$ in low positive $(21-50$ $\mathrm{mIU} / \mathrm{ml})$, and $6 \%$ in the gray area $(11-20 \mathrm{mIU} / \mathrm{ml})$.

In a study carried out on health workers in Spain in 1998 , it was found that $95.9 \%$ of individuals under 40 years of age developed HBsAb and only $90.4 \%$ of those over that age did. (6). A study that was carried out on 165 health workers of the CASE-ESSALUD National Hospital in Arequipa-Peru, shows that 98.9\% of workers under 40 years of age presented seroprotection compared to workers over 40 years of age, whom only $89.2 \%$ presented seroprotection. ${ }^{14}$

\section{CONCLUSION}

The distribution of the population according to gender was greater for the female; the age range with greater frequency was between 20 and 25 and the type of population with the highest participation was that of students.

Regarding the level of immunization, less than half of the participants have ideal protection (200 or more $\mathrm{mIU} / \mathrm{ml})$. The lowest percentage is located in the gray area $(11-20 \mathrm{mIU} / \mathrm{ml})$. When comparing gender, a higher percentage is shown in protected women than in men. When analyzing the age range, it was found that from 31 to 35 years there is a higher percentage of protected participants.

Regarding the KAP strategy, knowledge about Hepatitis B; was represented in the acceptable rating, insufficient attitudes, and outstanding practices.

\section{ACKNOWLEDGEMENT}

Majid Alhomrani would like to acknowledge TURSP (2020/257). The authors are also thankful to AlMaarefa University in Riyadh for providing support to do this research. 


\section{CONFLICT OF INTEREST}

The authors declare no conflict of interest.

\section{ABBREVIATIONS}

BMI: Body Mass Index; IU: International Units; KAP: Knowledge, Attitudes, Practices; HBsAg: Hepatitis B surface antigen;ELISA: Enzyme-linked immunosorbent assay.

\section{REFERENCES}

1. Ljunggren KE, Patarroyo ME, Engle R, Purcell RH, Gerin JL. Viral hepatitis in Colombia: a study of the "hepatitis of the Sierra Nevada de Santa Marta". Hepatology. 1985;5(2):299-304. doi: 10.1002/hep.1840050225, PMID 3979961.

2. Liaw Y-F, Chu C-M. Hepatitis B virus infection. Lancet. 2009;373(9663):582-92. doi: 10.1016/S0140-6736(09)60207-5.

3. Craven DE, Awdeh ZL, Kunches LM, Yunis EJ, Dienstag JL, Werner BG, Polk BF, Syndman DR, Platt R, Crumpacker CS. Nonresponsiveness to hepatitis $B$ vaccine in health care workers. Results of revaccination and genetic typings. Ann Intern Med. 1986, Dienstag, et al;105(3):356-60. doi: 10.7326/0003-4819-105-3-356, PMID 2943202.

4. Shepard CW, Simard EP, Finelli L, Fiore AE, Bell BP. Hepatitis B virus infection: epidemiology and vaccination. Epidemiol Rev. 2006;28(1):112-25. doi: 10.1093/epirev/mxj009, PMID 16754644.

5. Terrault NA, Lok ASF, McMahon BJ, Chang KM, Hwang JP, Jonas MM, Brown RS, Bzowej NH, Wong JB. Update on prevention, diagnosis, and treatment of chronic hepatitis B: AASLD 2018 hepatitis B guidance. Hepatology. 2018;67(4):1560-99. doi: 10.1002/hep.29800, PMID 29405329.

6. Badur S. Secretariat V. Burden and prevention of Viral Hepatitis in Turkey. Viral Hepat. 2010;18(2):1-28
7. West DJ, Calandra GB. Vaccine induced immunologic memory for hepatitis B surface antigen: implications for policy on booster vaccination. Vaccine. 1996;14(11):1019-27. doi: 10.1016/0264-410x(96)00062-x, PMID 8879096.

8. Garcia D, Porras A, Rico Mendoza AR, Alvis N, Navas MC, De La Hoz F, De Neira M, Osorio E, Valderrama JF. Hepatitis B infection control in Colombian Amazon after 15 years of hepatitis $B$ vaccination. Effectiveness of birth dose and current prevalence. Vaccine. 2018;36(19):2721-6. doi: 10.1016/j.vaccine.2017.11.004, PMID 29609968.

9. Coates T, Wilson R, Patrick G, André F, Watson V. Hepatitis B vaccines: assessment of the seroprotective efficacy of two recombinant DNA vaccines. Clin Ther. 2001;23(3):392-403. doi: 10.1016/s0149-2918(01)80044-8, PMID 11318074.

10. Lama JR, Agurto HS, Guanira JV, Ganoza C, Casapia M, Ojeda N, Ortiz A, Zamalloa V, Suarez-Ognio L, Cabezas C, Sanchez JL, Sanchez J, Peruvian HIV Sentinel Surveillance Working Group. Hepatitis B infection and association with other sexually transmitted infections among men who have sex with men in Peru. Am J Trop Med Hyg. 2010;83(1):194-200. doi: 10.4269/ ajtmh.2010.10-0003, PMID 20595501.

11. Abeje G, Azage M. Hepatitis B vaccine knowledge and vaccination status among health care workers of Bahir Dar City Administration, Northwest Ethiopia: a cross sectional study. BMC Infect Dis. 2015;15(1):30. doi: 10.1186/ s12879-015-0756-8, PMID 25637342.

12. Cadavid-Betancur DA, Ospina MC, Hincapié-Palacio D, Bernal-Restrepo LM, Buitrago-Giraldo S, Perez-Toro O, Santacruz-Sanmartín E, Lenis-Ballesteros V, Almanza-Payares R, Díaz FJ. Seroprevalence of hepatitis B and factors potentially associated in a population-based study in Medellín, Colombia. Vaccine. 2017;35(37):4905-12. doi: 10.1016/j.vaccine.2017.07.084, PMID 28780978.

13. Acevedo G, Farias A, Demaria MJ. Estado de vacunación en profesionales técnicos del equipo de salud de Hospitales estatales de la Provincia de Córdoba, Argentina. Rev Salud Publ. 2015;19(3):21-31.

14. Gutiérrez $M$, Tajada $P$, Alvarez $A$, De Julián $R$, Baquero $M$, Soriano V, Holguín $A$. Prevalence of HIV-1 non-B subtypes, syphilis, HTLV, and hepatitis B and C viruses among immigrant sex workers in Madrid, Spain. J Med Virol. 2004;74(4):521-7. doi: 10.1002/jmv.20208, PMID 15484270.

\section{SUMMARY}

The female population was more evenly distributed by gender; the age range with the greatest frequency was 20 to 25 years old. Regarding the KAP strategy, knowledge about Hepatitis B; was represented in the acceptable rating, insufficient attitudes, and outstanding practices.

Cite this article: Harsha S, Epstein IK, Asdaq SMB, Alamri AS, Alsanie WF, Alhomrani M. Titration of Antibodies and Application of the KAP Strategy for Hepatitis B in Students and Teachers. Indian J of Pharmaceutical Education and Research. 2021;55(3s):s646-s651. 